\title{
USING ALGORITHMS TO ANALYSE THE VISUAL PROPERTIES OF A BUILDING'S STYLE
}

\author{
CHRIS TUCKER \\ School of Architecture and Built Environment \\ University of Newcastle \\ University Drive, Callaghan, NSW 2328, Australia
}

Chris.Tucker@newcastle.edu.au

\section{MICHAEL OSTWALD}

School of Architecture and Built Environment University of Newcastle

University Drive, Callaghan, NSW 2328, Australia

Michael Ostwald@newcastle.edu.au

\begin{abstract}
Residential development within heritage conservation areas is regulated by Development Control Plans (DCP) that provide guidelines about the shape and form that new houses, alterations and additions should take (DIPNR 2004). By understanding that the visual amenity of streets within a city plays an important role in creating a sense of place and community for its citizens (Lynch 1960) they attempt to sustain, through regulation, an urban pattern that has become valued by the community. The visual character of a building within a streetscape is often associated with the style of its construction - a set of visual characteristics that a group of buildings might share. These characteristics include the relationship of the parts of the building to each other, and to the building as a whole, the use of ornament and visible textures, and the scale of elements within the composition.

Using algorithms developed within robotic research that enable a computer to interpret a visual environment (similar to those used in medicine and facial recognition for instance), this paper outlines how algorithms can be used to study the visual properties of the built environment. One of the methodological qualities of computer visualisation that makes it so useful for a comparative visual analysis of buildings is that the representational and symbolic meanings of a buildings style play no part. The organisation of the elements can be analysed without having to interpret their possible meaning at the beginning of the process.

This paper builds on an established interdisciplinary approach, utilising architectural knowledge and computer visualisation to evaluate the visual character of detached housing within a heritage conservation area. The visual environment is analysed using computer software developed to locate the visual boundaries within a view of a streetscape both as an elevation and aerial view.
\end{abstract}

Keywords: Streetscape, visual analysis, architectural style. 


\section{Introduction}

Planning authorities use words like sympathetic, compatible, historically significant, sense of place or identity when evaluating streetscape character. However such descriptions are necessarily subjective and qualitative, leading to extensive debate and limited objectivity.

How new buildings relate to existing urban settings has become an important point of debate in architectural, planning and public policy forums (Groat, 1988). In difference to new buildings within the natural landscape, or those that are visually removed from the public space of the street, buildings that infill urban and suburban streets visually relate to nearby buildings and become part of the existing streetscape. In a legislative or policy sense the definition of streetscape, as described in the Environmental Planning and Assessment Act is: the character of a locality defined by the "spatial arrangement and visual appearance of built and landscape features when viewed from the street" (Env. Planning Act, 1979). For parties in dispute over the effect of proposed building works within a streetscape, this definition becomes a critical and potentially costly factor (DIPNR, 2004; VicD.I., 2001). Such policies and practices signal the importance of determining some measure or dimension that could be used for describing or defining the visual character of a streetscape. Only by defining these processes more clearly can creative solutions be found for new buildings in areas with a well-established street character (RAIA, 2004).

\section{Visual Character of the Streetscape}

\subsection{Qualitative Measures}

While planning diagrams concentrate on the functional and formal requirements of the built landscape, little attention is given to obtaining information about the visual character of the urban environment. Aside from issues purely concerned with visual character, knowing the shape and materials of the built environment might inform urban sustainability issues such as space use and energy consumption. Fisher-Gewirtzman, Burt and Tzamir (Fisher-Gewirtzman, 2003a) adds that "quantitative parameters" such as: the penetration of natural light, wind intensity and density measurements, need to be related to other physical and psychological "qualitative parameters" such as texture, privacy, colour, and nostalgia. Quantitative measures such as the height of a proposed building and other density measures can be determined quickly and accurately. However, measuring the qualitative aspects of the built environment, such as visual character, are open to the interpretation of the individual. Because they are difficult to measure they can be overlooked, resulting in changes that disassociate residents from their "place based communities" (Hull IV, 1993). In cases where the character of a street or locality requires improvement, the challenge is to identify the physical attributes of the preferred character while developing the broader infrastructure and amenity within the locality (Townsend, 2001).

\subsection{Analysing Visual Character}

Establishing the existing visual character of a streetscape involves a two-step process. The first might be considered as a visual reading of the elements within the streetscape, a process that by its description might allow an objective analysis and a measurable outcome. The second stage involves a decision about the importance of the patterns of elements in relation to others (Alexander, 2003; DIPNR, 2004; VicD.I., 2001). This second stage of the process may remain a subjective analysis; the emphasis that each local government authority places on the importance of visual character will change, as will the meanings that each individual takes from a given scene. However, for buildings to be approved, planning authorities must assess these qualitative aspects of existing urban areas such that decisions can be made about proposed changes. It is this first stage that our research is concerned with, and in particular how the visual properties of a streetscape might be interpreted without first having to interpret its 'style'.

When new buildings are proposed in heritage conservation areas, development is regulated by Development Control Plans (DCP) that provide guidelines about the shape, form and detail that new houses, alterations and additions should take (DIPNR 2004). By understanding that the visual amenity of streets within a city plays an important role in creating a sense of place and community for its citizens (Lynch 1960) they attempt to sustain, through regulation, an urban pattern that has become valued by the community. 


\subsection{Surfaces of the Streetscape}

Urban open spaces are usually defined by the volume of empty space separated by the built surfaces. Teller (Teller, 2003) reflects on this stating that the form of a space is characterised by the relationship of "filled elements" that are within it. Salingaros (Salingaros, 1999b) similarly states that it is the information within the surrounding surfaces of the open space that is perceived, and is of greater importance than an analysis of a plan that is not perceived at all. While Hillier (Hillier, 1984:p1) rejects this based on a building's purpose, which he states is to transform space. The importance of visual perception to inform a building's purpose has been discussed by Lynch (1960:p4), Venturi (1966:p19), and Alexander (1977) in some detail. Differentiations in the surface of the open space caused by colour, texture and ornamentation are considered significant subdivisions within the surface of the streetscape even when their effect on its form may be minimal (Moughtin, 1999; Salingaros, 1999b). Surfaces of the open space that are orientated perpendicular to movement create a local spatial boundary (Salingaros, 1999b); a spatial type that Alexander calls "positive space", which is a fundamental property of coherent urban spaces. Theil, Harrison and Alden (Theil, 1986) state that the visual boundaries within the surface of a space define its degree of enclosure in a more significant way than simply determining how large it is. Research undertaken by Al-Homoud, and Natheer (2000) supports this by finding that vertical objects 'determine our perception of spatial enclosures' more than horizontal elements within urban spaces do.

\subsection{Texture of the Streetscape}

Texture is a property of all surfaces and is one of the characteristics used to identify visual regions bound by edges within an object. Depending on the scale of the visual information, both symmetry and simplicity can be accounted for in terms of analysis of texture (Schira, 2003). It can be described as the 'structural arrangement of a surface and the relationship that one arrangement has with others surrounding it' (Schira, 2003).

So does replicating a Federation house within a streetscape dominated by federation houses provide a satisfactory outcome for the visual character of the street? This is a debate with wide ranging views, but from a planning perspective, replication of an existing style is considered an acceptable and often desirable solution (Alexander, 2003). Architects might disagree with the premise of this planning solution (RAIA, 2004), but to satisfy the requirements of the planning process, the visual qualities of contemporary buildings must be understood, and they must be understood in relation to the existing visual context.

Craglia, Leontidou, Nuvolati and Schweikart (Craglia, 2004) reflect on the "reinvention of tradition as one of the strategies to enhance visibility" based on the market driven by the "urban tourist", as opposed to the more traditional resident. These sometimes conflicting requirement of the city have drawn a distinction between the modernist tendency to regulate space based on zoning to a post-modern approach where "fragmentation, urban mosaics and the colourfulness of cultural difference" (Craglia, 2004) are encouraged. Craglia et al. point out that this "recognition of differences has resulted in a cultural shift in urban studies with the city analysed as a work of art, a representation, and a text, that take different meanings for the various actors in it'. Urban planning ideas originally proposed by Sitte (1945), Lynch (1960), Jacobs (1961) and Alexander et al. (1977) are now being discussed from a commercial point of view (Craglia, 2004).

However, Hildebrand (Hildebrand, 1999) offers a reflection on this; he maintains that successful architecture results from an abstract drive to impose patterns on surfaces, that otherwise appear to be random acts of inhabitation. These patterns are the physical attributes of buildings, and help to identify visual regions of interest, that subsequently make them appealing or not (Schira, 2003). Salingaros (Salingaros, 1999b) comments that contemporary building materials and methods used to replicate traditional façade styles might 'minimize the information field' and subsequently not provide the visual field associated with the traditional building. This is an important issue and expands the discussion of streetscape character beyond purely the formal attributes of buildings.

\subsection{The Significance of Detail Within the Façade of Buildings}

Many researchers have shown that the character of a building often depends on the detail within its façade (Stamps III, 1999). For instance, Brolin (Brolin, 2000) suggests that the visual texture 'composed primarily of small scale details' is the most critical factor to consider when locating a new building within an existing built context. Methods used in architecture to 
determine scale within a building include massing, where the largest scale is usually defined by an outline of the building itself (Salingaros, 2000b). Elements within the façade such as openings, detail, trim and the material itself will then successively identify smaller scales.

Symmetry is a condition of massing and is manifested through the recurrence of shapes in a regular way, and can help connect elements forming a single element at a greater scale (Salingaros, 2000b). Once formed, this arrangement can be thought of as modular, repeated through the 'economy of thought and action' (Salingaros, 2001)

Bentley (Bentley, 1987) suggests that 'richness' can be created through details within the walls that incorporate patterns of material and colour. Moughtin et al. (Moughtin, 1999:p25) suggests that decoration, ornamentation and articulation within a building's façade is the 'means by which a variety of visual experiences are introduced to the viewer'. Hull et al. ((Hull IV, 1993) found that decorative style or other distinguishing physical characteristics were highly valued by the residents of houses, and were perhaps highly valued because they distinguished one place from another.

Stamps states that while empirical work on architectural detail is sparse it tends to support the hypothesis that 'detail is an important part of preferences for buildings' (Stamps III, 1999). Salingaros (2003b) reflects that ornamentation 'connects us to our environment'. Also, that successful building facades within an urban space feature a 'continuous swath of high-density visual structure that the eye can follow in traversing their overall form, or focal points of intense detail and contrast arranged in the middle or at the corners of regions' (Salingaros, 2003b). He has shown that ornament and decoration 'subdivide building façades on many different scales' and that the most effective hierarchical scaling creates a fractal geometry (Moughtin, 1999; Salingaros, 1999b) which is independent of any associated scale.

The location of larger details within the façade such as doors and windows are important elements within the urban fabric as they offer the opportunity for natural surveillance of the urban space, reducing the likelihood of crime (Newman, 1972:p80). Whether actual surveillance takes place may be difficult to determine, but the capacity for buildings to provide the opportunity is an important aspect of 'natural surveillance' (Newman, 1972).

\subsection{Visually Assessing the Character of a Streetscape}

Ellefsen (Ellefsen, 1991) states that planning authorities have a need for specific and objective information about the character of urban buildings and their settings when they undertake studies of the local environment. Understanding that the visual characteristics of streetscapes effect social life within the street has been recognised as an important way of revitalizing urban areas that are socially dysfunctional (Healy, 2004). However, methods that clearly articulate how the physical character or aesthetics of a streetscape might be evaluated and then compared with another are difficult to find. Lillis, and Pourmoradian (Lillis, 2001) found that techniques currently used for streetscape analysis did not establish the basic information required by planning authorities and community groups for informed decision making about changes to the streetscape. They proposed a "toolkit" that relied on a checklist of commonly found elements within the streetscape. An individual would use the checklist to record the visual aspects of the street, but how this information would be used by a designer to develop a new design is difficult to understand. As Stamps (Stamps III, 2003) reflects, those verbal and notated descriptions will eventually become 'physical materials in physical space'.

\section{Methods for Assessing the Visual Properties of Streetscape Images}

Computer software has been developed that utilises architectural knowledge and computer visualisation to analyse images of the streetscape. The images and description below shows the different ways that the image is analysed to reveal some of its visual properties. Figures 2 12 are an analysis of the image shown in Figure 1.

Figure 2 shows how colours within the image can be identified and grouped to find the proportion they occupy. In Figure 2 colours have been classified as cladding, detail within the cladding, trim and surfaces in shadow. Segmenting the image based on colour can show the proportion of a buildings surface that is exposed to sunlight, covered by vegetation or of a particular construction, such as glazed. Figure $\mathbf{9}$ shows a screen from the software that allows the original image to be 'mouse clicked' to accumulate the colour classification required.

Figures 3 shows the conversion of the original image into a diagram where edges, or areas of high contrast between adjacent pixels, are highlighted. This process eliminates areas of low 
contrast, or regions where edges in the image are not found (the middle of a surface for instance). This diagram can then be processed using the Hough Transform (HT). Figure 5 shows the Hough acculumator, the resulting graph after the HT has been applied to Figure 3. The Hough Transform is an algorithm that detects the likely direction of a line (or edge) that any pixel in the image might be part of (Tucker, 2005a). It shows the angle and distance of all pixels within detected lines from a predetermined origin. Lines with the greatest number of edge pixels within them appear as 'bright' points within the array. This process finds edges that are continuous (such as the roof line) and those that are discontinuous (such as the virtual horizontal line formed by the tops of closely spaced vertical fence palings). Detecting lines that are discontinuous, but perceived by humans as an edge, is an important part of Gestalt psychology (Chalup, 2007; Guy, 2002) and necessary for a visual analysis of existing buildings (Tucker, 2004). The HT also translates lines (or edges) within the image into points, making the array a diagram that can be compared with others. Finding similarities and differences between the diagrams enables them to be clustered, showing where dwellings of the same or dissimilar architectural styles might share particular visual characteristics (Chalup, 2007).

Determining whether an image of the streetscape exhibits more horizontal or vertical lines can be related to feelings of privacy (verticality) or publicity (horizontality) (Al-Homoud, 2000).

Figure 6 is the Hough accumulator array expressed as a polar graph. This locates the angle and strength of the found line in relation to the centre of the image - the size of the bubble relating to its strength. Figure 7 shows a diagram that considers every pixel in the image as being part of a possible line within the image. By successively eliminating lines that contain only 3 pixels, then 4 and so on, the diagram shows peaks at the most dominate lines at a given angle. This graph is useful for showing where there may be a high density of relatively small line lengths, and how the density of line length is distributed throughout the image. When comparing traditional dwellings, such as a federation terrace, and a modern suburban dwelling this density of visual information can differentiate the two styles (Tucker, 2005a). Figure 8 shows the graph of line length without considering the angle of the line.

Figure 10 shows the inverse Hough Transform where the dominant found lines (of infinite length) are placed back over the original image.

Figure 4 shows a calculation of the fractal dimension using the box counting method. The automated technique develops the work undertaken by Bovill and Weidemann (Bovill, 1996) and uses methods developed by Fouroutan, Dutilleul and Smith ((Foroutan-pour, 1999) to determine the best approximation for the fractal dimension. Salingaros et al (Salingaros, 1999a) has discussed the relationship between a higher fractal dimension and successful urban spaces. Figure 11 \& 12 show the grid (of varying size) is placed over the image to calculate the fractal dimension. 


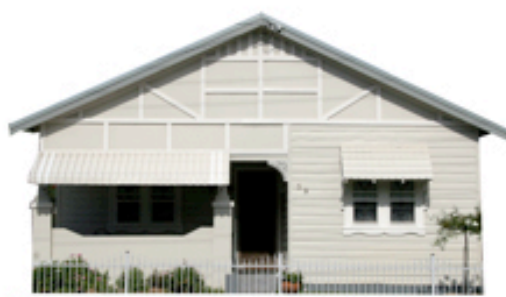

Figure 1 Original image 1

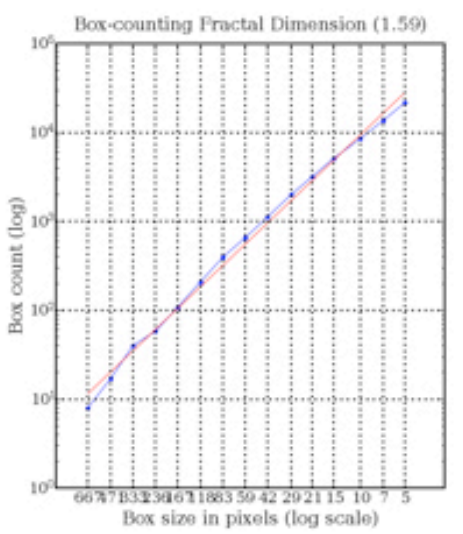

Figure 4 Fractal calculation

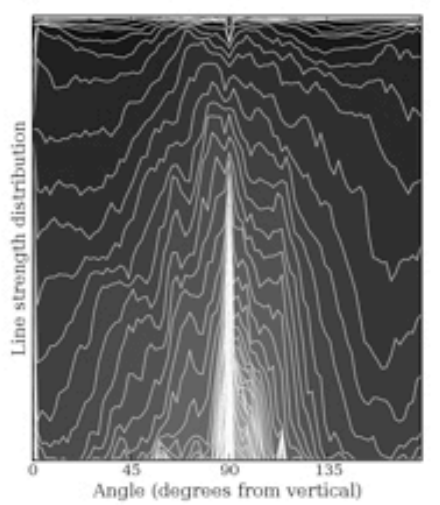

Figure 7 Edge length distribution

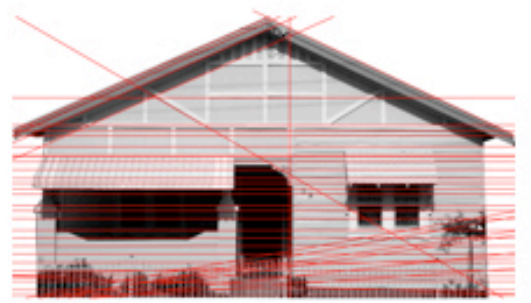

Figure 10 Inverse HT 1

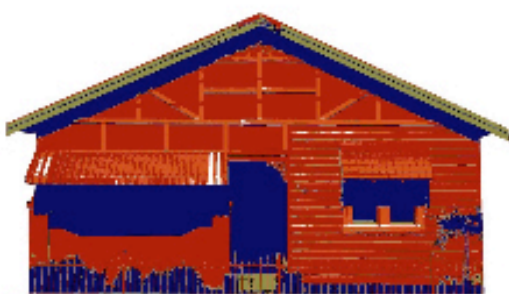

Figure 2 Colour classification

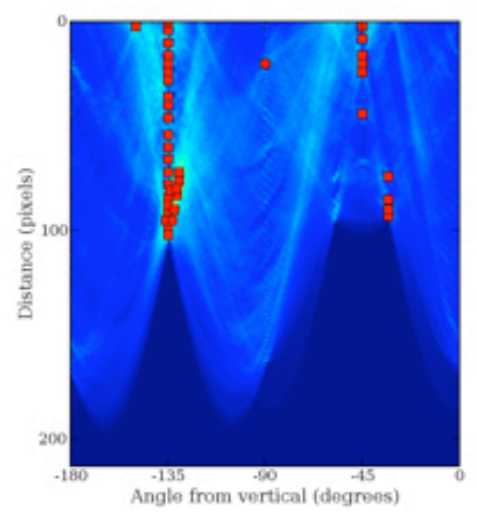

Figure 5 Hough array

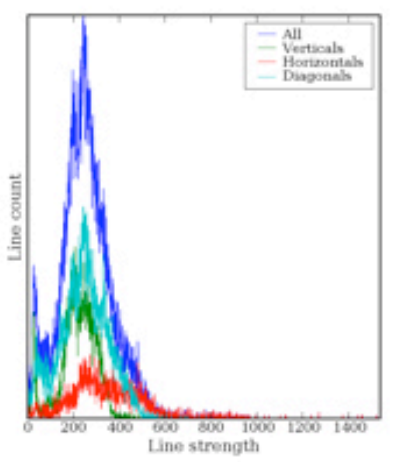

Figure 8 Edge count

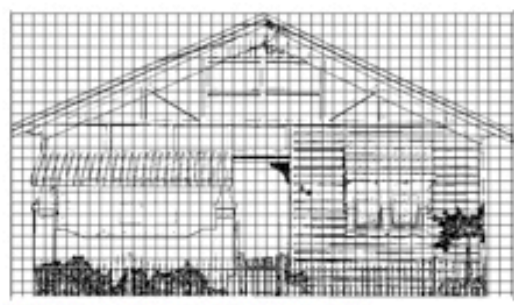

Figure 11 Box counting

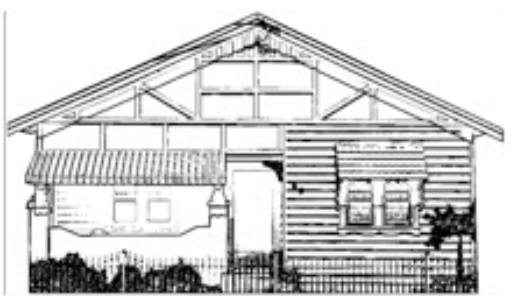

Figure 3 Edge detection

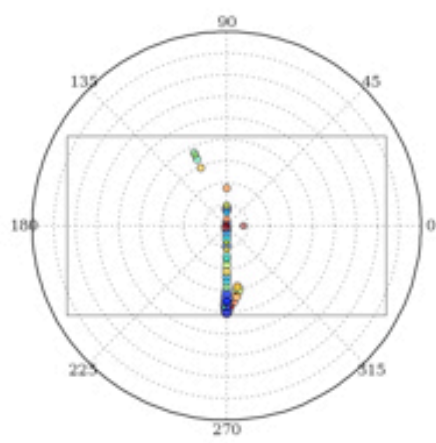

Figure 6 Polar Hough Array

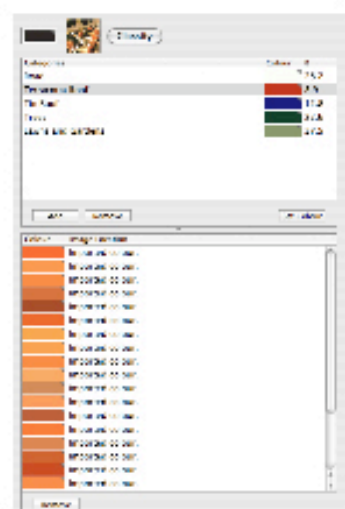

Figure 9 Classification screen

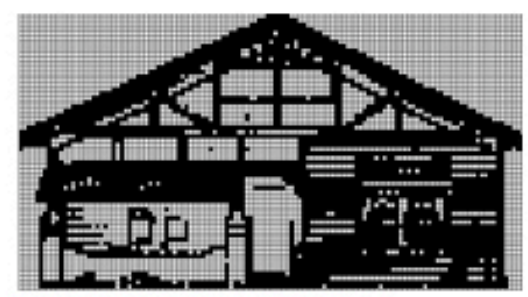

Figure 12 Box counting 


\subsection{Recognising detail within a dwellings facade}

An example of how the HT can be used to distinguish dwellings is shown in Figures $13-18$. Figures 13 \& 16 show neighbouring houses that would have been constructed at the same time, in the same way and in the same form and detail. Over time they have undergone some changes and while recognisable as the same house appear visually different. The differences in horizontal and vertical elements is shown clearly with the HT analysis shown in Figures 14 \& 17. Using this analysis the detail within the façade is emphasised over the formal structure, more clearly shown in Figures 15 \& 18 where the original image is removed from the inverse HT.

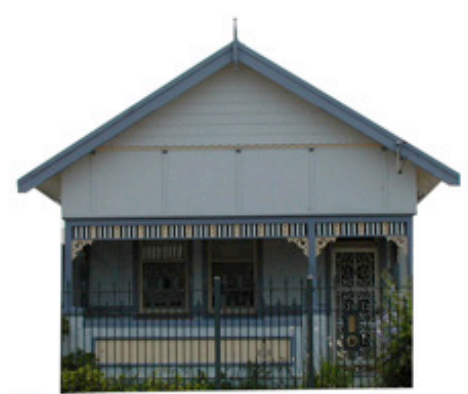

Figure 13 Original image 2

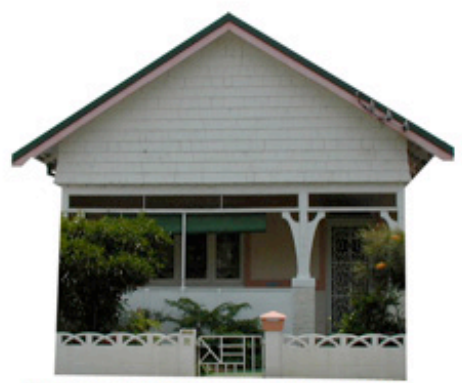

Figure 16 Original image 3

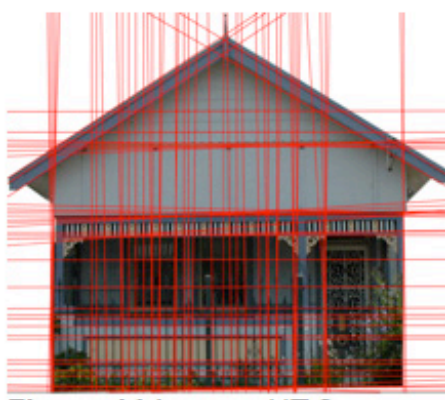

Figure 14 Inverse HT 2

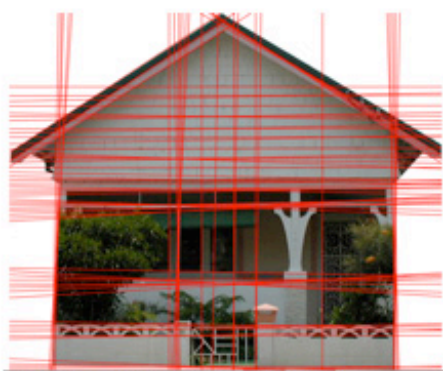

Figure 17 Inverse HT 3

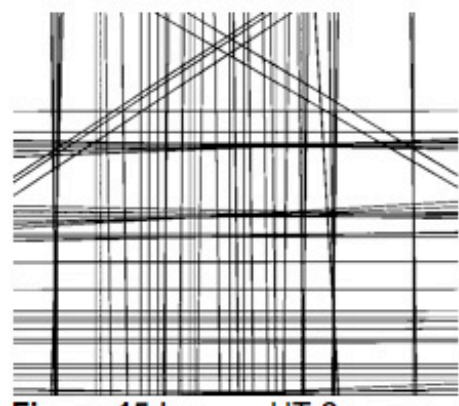

Figure 15 Inverse HT 2

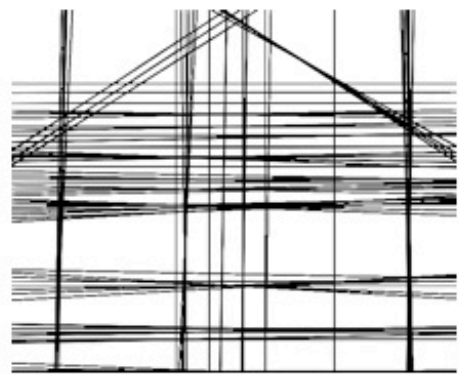

Figure 18 Inverse HT 3

\subsection{Colour Segmentation of Aerial Photographs Based on User Selected Classification}

Grouping colours within the image that represent a particular visual characteristic provides information about how common the characteristic is within the image. For instance Fig 19 shows an aerial view of the Hamilton South Conservation Area (HSCA marked with black outline). The HSCA has developed planning controls but does not differentiate between areas within the conservation area that might have a different visual character. The visual character does appear to gradually change when assessing the streetscape, and by analysing the aerial map using colour segmentation, some differences become clear. The analysis shows in Fig 22 that the naming of a suburb has a marked effect on the style of dwelling that was constructed in the area - the black outline showing the suburb boundaries. Metal rooves ( + timber walls) dominate in the suburb of Merewether compared with the terracotta rooves (+ masonry walls) of houses in Hamilton.

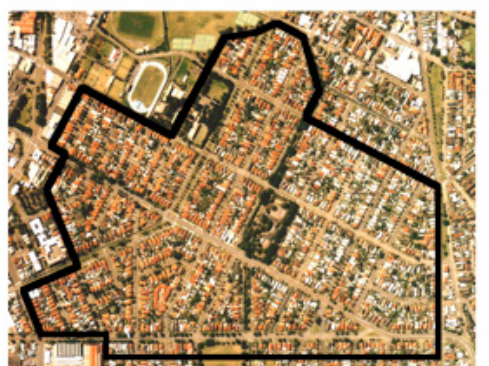

Figure 19 Conservation area

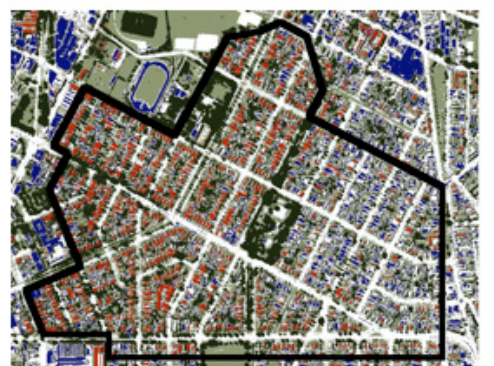

Figure 20 Colour segmentation

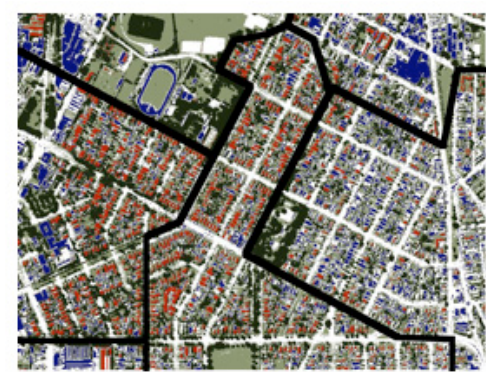

Figure 21 Suburb layout 
The graph below shows how the proportion of hard surfaces, street trees, lawn, metal roofs and tiled roofs vary when 12 adjacent blocks are analysed.

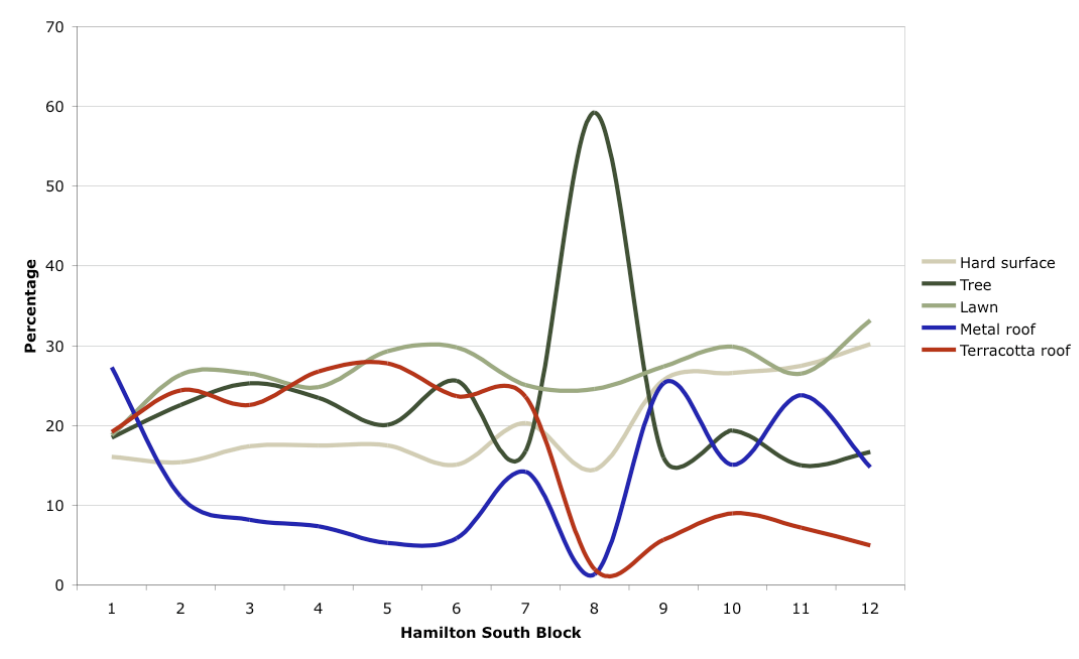

Figure 22 Graph of variation in colour over 12 blocks within the HSCA

\section{Future work}

Analysing the visual properties of modern and traditional buildings can show where they share certain visual characteristics, providing a planning argument for why a contemporary building, for instance, can sustain the heritage value of a streetscape within a conservation area. Understanding the visual characteristics of the built environment within heritage conservation areas might allow new buildings to be proposed that are of a different style, but none the less retain the visual character of the area.

The different methods of visual analysis outlined in this paper are being brought together as a single software platform, where an image can be processed and compared with another. Analysing all buildings within a street or locality in this way provides an analysis of the visual environment that has previously not been possible. Analysing the visual properties of modern and traditional buildings can show where they share certain visual characteristics, providing a planning argument for why a contemporary building, for instance, can sustain the heritage value of a streetscape within a conservation area. Understanding the visual characteristics of the built environment within heritage conservation areas might allow new buildings to be proposed that are of a different style, but none the less retain the visual character of the area.

\section{References}

Act, E. P. a. A. Environmental Planning and Assessment Act. 1979.

Al-Homoud, M. A.-O., Natheer. "Sense of privacy and territoriality as a function of spatial layout in university public spaces." Architectural science review 43 (4) (2000): 211-219.

Alexander, N., Stark, P. Neighbourhood Characters - Multi- or Mono-Cultural. Paper presented at the Planning with Diversity: Adelaide 2003, Adelaide, 2003.

Bentley, I., Alcock, A., Murrain, P., McGlynn, G. Responsive environments: a manual for designers. London: Butterworth-Architecture, 1987.

Bovill, C. G., A.E. Wiedemann, G. Fractal geometry in architecture and design. Boston: Birkhauser, 1996.

Brolin, B. Architectural ornament: banishment and return. New York: Norton, 2000.

Chalup, S., Clement, R., Marshall, J., Tucker, C., Ostwald, M. Representations of Streetscape Perceptions Through Manifold Learning in the Space of Hough Arrays. Paper presented at the IEEE Symposium on Artificial Life, Honolulu, Hawaii, USA, April 1- 42007. 
Craglia, M., Leontidou, L., Nuvolati, G., Schweikart, J. "Towards the development of quality of life indicators in the 'digital' city." Environment and Planning B, Planning and Design, 31 (2004): 51-64.

DIPNR, N. Neighbourhood Character. Sydney: NSW Department of Infrastructure Planning \& Natural Resources. 2004.

Ellefsen, R. "Mapping and Measuring Buildings in the Canopy Boundary Layer in Ten U.S Cities." Energy and Buildings, 15-16 (1991): 1025-1049.

Fisher-Gewirtzman, D., Burt, M., Tzamir, Y. "A 3D visual method for comparative evaluation of dense built up environments." Environment and Planning B, Planning and Design 30 (2003a): 575-587.

Foroutan-pour, K., Dutilleul, P., Smith, D.L. "Advances in the implementation of the box-counting method of fractal dimension estimation." Applied Mathematics and Computation 105(2-3) (1999): 195-210.

Groat, L. "Contextual compatibility in architecture: an issue of personal taste?" In J. Nasar (Ed.), Environmental aesthetics: Theory, research, and applications. Cambridge: Cambridge University Press, (1988): 228-253.

Guy, B. The Demystification of Character. Paper presented at the Planning Research Conference, Dundee, 2002.

Healy, E., Birrell, B. Housing and Community in the Compact City (Positioning paper). Melbourne: Australian Housing and Urban Research Institute, 2004.

Hildebrand, G. Origins of Architectural Pleasure. Berkeley CA: University of California Press, 1999.

Hillier, B., Hanson, J. The social logic of space. Cambridge, NY: Cambridge University Press, 1984.

Hull IV, R., Lam, M., Vigo, G. "Place identity: symbols of self in the urban fabric." Landscape and Urban Planning 28 (1993): 109-120.

Lillis, J., Pourmoradian, S. 'Pedsafe' - Development of a new pedestrian auditing method. Paper presented at the Conference of Australian Institutes of Transport Research, Melbourne, 2001.

Moughtin, C., Taner, O., Tiesdell, S. Urban Design: Ornament and Decoration (Second ed.). Oxford: Architectural Press, 1999.

Newman, O. Defensible Space. London: Architectural Press, 1972.

RAIA. Development (Sustainable Development) Amendment Bill 2004. Adelaide, 2004.

Salingaros, N. "Urban space and its information field." Journal of Urban Design 4 (1999b): 2949.

Salingaros, N. "Hierarchical cooperation in architecture, and the mathematical necessity for ornament." Journal of architectural and planning research 17 (2000b): 221-235.

Salingaros, N. X. "Modularity and the Number of Design Choices." Nexus Network Journal 3 (2) (2000b).

Salingaros, N. "The sensory value of ornament." Communication and Cognition 36 (2003b).

Salingaros, N., West, B. "A universal rule for the distribution of sizes." Environment and Planning B, Planning and Design 26 (1999a): 909-923.

Schira, G. "Texture preference and global frequency magnitudes." Environment and Planning B, Planning and Design 30 (2003): 297-318.

Stamps III, A. "Architectural detail, Van der Laan septaves and pixel counts." Design Studies 20 (1999): 83-97.

Stamps III, A. "Advances in visual diversity and entropy." Environment and Planning B, Planning and Design 200330 (2003): 449-463.

Teller, J. "A spherical metric for the field-orientated analysis of complex urban open spaces." Environment and Planning B, Planning and Design 30 (2003): 339-365. 
Theil, P. H., Ean Duane; Alden, Richard S. "The Perception of Spacial enclosure as a function of the position of architectural Surfaces." Environment and Behavior 18 (2) (1986).

Townsend, L. "The evolution of neighbourhood character." Landscape Australia 23 (4) (92) (2001): 11-16.

Tucker, C., Ostwald, M., Chalup, S. A method for the visual analysis of streetscape character using digital imaging processing. Paper presented at the Proceedings of the 38th Annual Conference of the Architectural Science Association ANZAScA and the International Building Performance Simulation Association, Launceston, Tasmania, 2004.

Tucker, C., Ostwald, M., Chalup, S., Marshall, J. A method for the visual analysis of the streetscape. Paper presented at the Space Syntax 5th International Symposium, Delft, Netherlands, 2005a.

VicD.I. Understanding Neighbourhood Character. Melbourne: Victorian Department of Infrastructure, 2001.

All images are owned by Chris Tucker. 